\title{
The Scottish Clinical Supervision Model for Midwives
}

\author{
Susan Key ${ }^{1}$ \\ Helene Marshall ${ }^{2}$
}

Caroline J Hollins Martin ${ }^{3}$

${ }^{1}$ Susan Key, Associate Director of Nursing Midwifery \& Allied Health Professions (NMAHP) at NHS Education Scotland (NES), Email: Susan.Key@nes.scot.nhs.uk

${ }^{2}$ Helene Marshall, Principle Educator for Women Children Young People \& Families (WCYPF) in NMAHP at NES, Email: $\underline{\text { Helene.Marshall@nes.cot.nhs.uk }}$

${ }^{3}$ Caroline $\mathrm{J}$ Hollins Martin, Professor of Maternal Health, School of Health and Social Care, Edinburgh Napier University(ENU). Email: c.hollinsmartin@napier.ac.uk 


\title{
The Scottish Clinical Supervision Model for Midwives
}

\begin{abstract}
Following a change in UK legislation, the Nursing and Midwifery Council (NMC) model of statutory supervision for midwives ceased in 2017. In response, the Scottish Government (SG) and NHS Education for Scotland (NES) worked with the NHS Health Boards to develop a new employer-led model of clinical supervision. The aim of this new model is to help midwives provide improved services, safer care and improved outcomes for childbearing women and infants in keeping with professional regulation. The new Scottish Clinical Supervision Model is also designed to increase midwives personal wellbeing and help them deal with everyday challenges of clinical practice. This design of supervision is a radical departure from the prior NMC model, given that it incorporates facilitation and coaching methods which teach midwives to respond, reflect, and restore self, and through doing so reduce stress and increase resilience. In an attempt to improve nurturing leadership, the key components of this new model are underpinned by a person-centred approach, during which the supervisor provides unconditional positive regard and empathy towards the supervisee. Equipping midwives to develop contemporary supervision is supported by NES through online education that can be accessed at: https://www.nes.scot.nhs.uk/education-and-training/by-theme-initiative/maternitycare/about-us/clinical-supervision.aspx
\end{abstract}

Key words: childbirth, empathy, midwifery, midwives, person-centred, Scotland, supervision, unconditional positive regard. 


\section{Key points}

(1) Removal of statutory supervision for UK midwives in 2017 left managers with responsibility for providing alternative methods of support to midwives in clinical practice.

(2) One aim of the supervisor is to support the midwife (supervisee) to reflect upon and develop their clinical practice in line with professional accountability and regulation.

(3) The NMC request that midwives write 5 reflections on practice for their 3yearly re-validation, with the Scottish Clinical Supervision Model designed to encourage midwives to reflect upon practice-based events within a safe environment.

(4) One feature of the model is to acknowledge stressors that can impact upon midwives' personal wellbeing.

(5) The new Scottish Clinical Supervision Model considers the importance of developing practitioners who know how to care for both self and others. Supervision in this context is not punitive, but instead involves a restorative component.

\section{Acknowledgements}

NHS Education Scotland (NES) would like to thank members of the Scottish Government (SG) and in particular Anne Holmes for her leadership, NHS Health Boards (HB) and the Lead Midwife Educators (LME) from the Scottish Universities for their help with developing this new employer led Scottish Clinical Supervision Model. 


\section{The Scottish Clinical Supervision Model for Midwives}

\section{Introduction}

Recent removal of statutory supervision for midwives has left maternity care managers with responsibility for ensuring that alternative processes of guidance were initiated to improve the quality of maternity care provided by midwives. Although the statutory elements of supervision have disbanded in the UK, this does not signify the end of supervision for midwives. In its place, NHS Education for Scotland (NES) co-ordinated development of a new supportive system of supervision that has now been rolled out over Scotland. The aim of developing this new Scottish Clinical Supervision Model is to facilitate midwives to provide improved services, safer care and better outcomes for women and families through encouraging advocacy and accountability in keeping with professional regulation. Changes to regulation of supervision in midwifery (NMC, 2017a) provided the opportunity to adopt a refreshed approach that focuses upon supporting midwives to reflect on clinical practice, at the same time as developing resilience. This new model takes a compassionate and person-centred approach, which is a revolutionary departure from the prior NMC supervision model. As part of the process, this new model incorporates coaching methods designed to help midwives respond, reflect, and restore self.

The contents of this paper are designed to capture the processes involved in the new Scottish Clinical Supervision Model (NES, 2019). The first and second authors directed its development in conjunction with a Steering Group. The underpinning education surrounding this new model can be accessed at: https://www.nes.scot.nhs.uk/education-and-training/by-theme-initiative/maternitycare/about-us/clinical-supervision.aspx

The overarching aims of the new NES Clinical Supervision Model (NES, 2019) are to: (1) improve services, deliver safer care, and benefit outcomes for childbearing women and infants, (2) to support the midwife (supervisee) to reflect upon and develop their clinical practice in line with professional accountability and regulation (SG, 2017), and (3) produce a system of supervision that cares for practitioners mental health. 


\section{So why is clinical supervision important?}

Both the NMC and Health and Care Professions Council (HCPC) for pre-registration midwifery request that clinicians reflect upon practice during re-validation (NMC, 2017b; HCPC, 2017). Also, the government documents Everyone Matters: 2020 Workforce Vision (SG, 2013) and Rights, Relationships and Recovery (SG, 2010) highlight the need to support and develop midwives using a model that embraces reflective practice. In response, the Scottish Clinical Supervision Model has been designed to acknowledge stressors that impact upon midwives' personal wellbeing, which is intended to improve self-care and enhance staff morale (SG, 2017). When used, the new Scottish Clinical Supervision Model promotes exploration of clinical incidents, whilst taking into consideration emotions aroused during an interaction or clinical event. Supervision in this context involves a restorative component, which encourages the midwife to communicate more effectively through exploration of scenarios (Raab, 2014). When used, the supervisor encourages the supervisee or group of supervisees to engage with the points illustrated in Figure 1 (NES, 2019a).

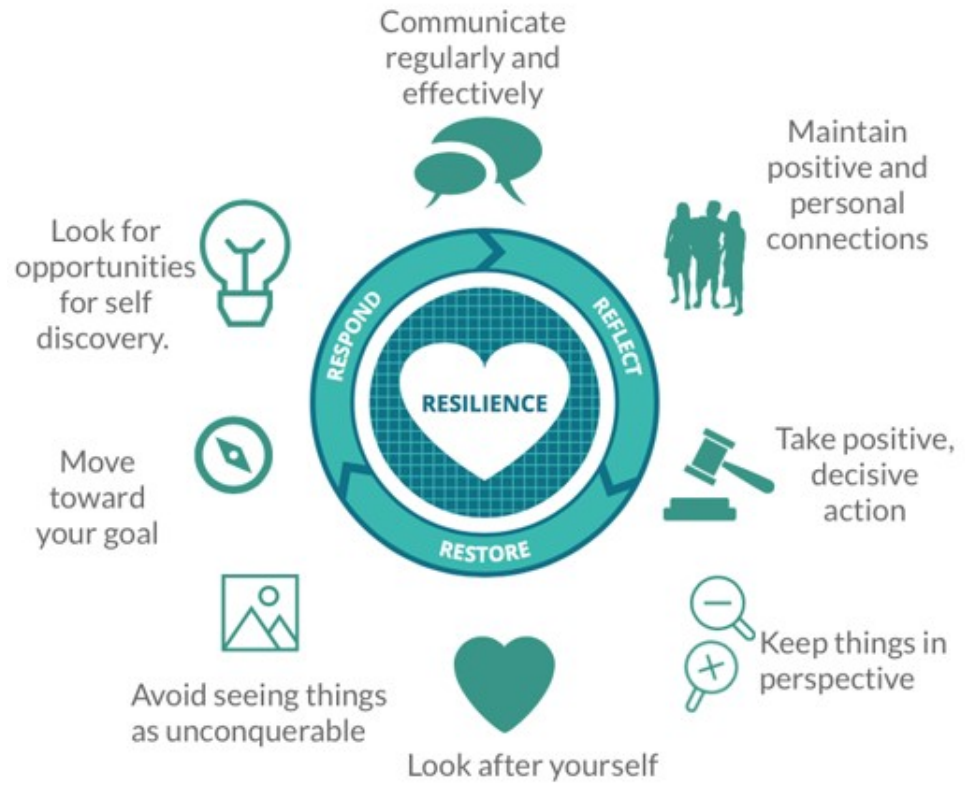

Figure 1: Goals for resilience building in the Scottish Clinical Supervision Model (NES, 2019a). 


\section{Processes involved in supervision}

Processes involve examining aspects that have touched the midwife emotionally. Emphasis is placed upon improving coping strategies and reducing compassion fatigue that stems from emotional, psychological, physical and spiritual exhaustion, which together and if ongoing can progress burnout (Klimek \& Singer, 2012) and impact upon performance and levels of kindness shown to others (Beaumont \& Hollins Martin, 2016). Essentially the Scottish Clinical Supervision Model has been designed to encourage midwives to reflect upon practice-based events within a safe environment, with learning gained designed to reduce work-related stress (Bishop \& Sweeny, 2006; Wallbank, 2010). As such, the benefits of 'super-vision' is about developing a 'super form of vision', during which the midwife can take a fresh look at a self-selected experience (Care Quality Commission, 2013). In addition, the restorative component helps equip the midwife with improved coping skills to better manage taxing clinical work (Sheen et al., 2014).

To maximise effectiveness, clinical supervision should take place in a safe space and use a structured reflection framework. When used, the midwife requires to be mutually supportive to peers, which involves being open to questions and challenge and being accountable. Clinical supervision involves reflecting upon events and examining what went well or otherwise and how improvements can be made. The Scottish Clinical Supervision Model (NES, 2019) should not be used as:

- A performance management tool.

- A method of managerial control.

- Part of a reporting process.

- An appraisal.

- A personal soap-box.

- A place for prying, blame or running colleagues down.

- A therapy (although the process may be therapeutic).

The process should be guided by a trained supervisor who understands how to use a reflective model in the context of a clinical incidence, with emphasis placed upon improving the supervisee's ability to provide care. 


\section{Setting up a system of clinical supervision}

The responsibility for setting up a system of clinical supervision rests with the delegated member of the organisation. It is recommended that sessions are approximately 1-hour monthly and led by a named supervisor. In Scotland, each Health Board (HB) is responsible for organising their own supervision framework. As such, the style of delivery may differ between HB's, with each independently responsible for selecting their own lead supervisor and system of delivery. Factors for consideration include whether supervision takes place in the midwives' worktime, in groups, or on a one to one basis. Group versions are negotiated, with some members electing to attend by Skype. These groups are often fixed, with change of members negotiated democratically. New supervisors are midwife volunteers, many of whom have worked in the old supervisor capacity. NES offer ongoing supervisors workshops, and there is the online training available on the internet site (NES, 2019). Outside of this, each HB is responsible for ensuring their staff are prepared and supported for their new role. At present, there are no formal assessments for qualifying as a new style supervisor, and midwives select whom they want from those available. A positive and quality relationship between supervisor and supervisee is essential to ensure effectiveness of the supervisory process, with midwives free to change their supervisor in certain circumstances. In the event that disharmony arises between supervisee and supervisor, either can reasonably request a change through negotiation with the HB supervisory lead. It is preferable that together they negotiate their own way through any issues. Supervision is intended to yield (NES, 2019):

- Improved practice through developing confident and knowledgeable midwives.

- Increased accountability and motivation.

- Enhanced well-being and reduced levels of sickness.

- Improved communication.

- Increased job satisfaction.

- Improved self-awareness and professional accountability.

- A culture where midwives feel valued.

- Improved recruitment and staff retention. 
Managers require to stipulate requirements for supervision in local policy and develop a system of documenting evidence of participation. Documenting events will allow revalidation and assessment of progress in relation to matters discussed. Completing a training program will strengthen supervisors' skills and ensure that they all have similar knowledge. Supervisors also require to be trained in management of group dynamics and how to apply reflective models. Proctor's Functions of Clinical Supervision Model is one of several tools that a supervisor can use. This model outlines a process of normative accountability, formative (learning), and restorative (support) (Marken \& Payne, 1988):

- Normative (accountability)

Focuses upon supporting the midwife to develop ability and effectiveness through reflecting on practice, with increased awareness of local policy and codes of conduct.

- Formative (learning) Implements an educative component which enables the midwife to develop insightfulness through guided reflection, designed to cultivate skills, knowledge, attitudes, and understanding of the clinical event.

- Restorative (support)

Is concerned with how the midwife responds emotionally to work associated with caring for others. The goal is to foster resilience through delivering encouragement and igniting motivation within a key supportive relationship.

\section{Steps involved in the Scottish Clinical Supervision Model}

There are 5 steps in process (see Table 1), with the first involving writing a contract between supervisor and supervisee (NES, 2019b). 
Table 1: Summary of steps involved in the Scottish Clinical Supervision Model (NES, 2019b)

\begin{tabular}{|l|}
\hline (1) Writing the CONTRACT: \\
(1a) Ground rules \\
(1b) Boundaries \\
(1c) Accountability \\
(1d) Expectations \\
(1e) Relationship \\
\hline (2) Maintaining FOCUS: \\
(2a) Issues \\
(2b) Objectives \\
(2c) Presentation \\
(2d) Priorities \\
\hline (3) The importance of SPACE: \\
(3a) Collaboration \\
(3b) Investigation \\
(3c) Challenge \\
(3d) Containment \\
(3e) Affirmation \\
\hline (4) Building a BRIDGE: \\
(4a) Consolidation \\
(4b) Information giving \\
(4c) Goal setting \\
(4e) Client's view \\
\hline (5) The REVIEW: \\
(5a) Feedback \\
(5b) Grounding \\
(5c) Evaluation \\
(5d) Assessment \\
\hline
\end{tabular}

\section{(1) Writing the CONTRACT}

Before supervision commences, a contract is drawn-up between supervisor and supervisee which establishes ground rules and priorities for discussion (Page \& Wosket, 2001). This process involves discussion of ground rules, boundaries, accountability, expectations, and the relationship between supervisor and supervisee. Examples of events appropriate to bring to supervision include a case study, a critical incident, an ethical issue, a legal matter, a reported event, a documentation issue, a clinical skills event, a decision-making difficulty, a confidence or competence struggle, a current topical event, a policy relating to maternity care, a leadership struggle, a career aspiration, or an issue of professional self-care. At commencement of the supervision process, it is important for supervisor and supervisee to negotiate some ground rules. 


\section{(1a) Ground rules}

The contract should reflect organisational and professional values (Hawkins \& Shohet, 2012) and outline purpose, regularity, duration, location, and under what circumstances it is acceptable to cancel a supervision session (Cassedy, 2010).

\section{(1b) Expectations}

The key purpose of writing the contract is to clarify expectations from the supervision relationship, with expectancies including:

- Regularity, duration and location of sessions.

- How confidentiality will be maintained and circumstances under which it can be broken.

- How records are kept and by whom.

- How clinical supervision will be reviewed and evaluated.

- Under what circumstances it is acceptable to cancel a session.

- How the supervisory relationship can be ended.

\section{(1c) Boundaries}

It is key that the supervisor (leader) maintains conversations within professional boundaries and where necessary respectfully challenges behaviours or values that raise concern. If group supervision is the selected method, it is important to consider whether members are open to new midwives joining and how this process will be managed, what constitutes respectful communication and how topics are chosen? Contracts will not ensure trusting participation, however negotiating and declaring them is an opportunity for clarifying intention and expectations (Proctor, 2011).

\section{(1d) Accountability}

Within the established paperwork, the midwife (supervisee) is accountable for outlining a clinical incident for exploration and list their objectives for the supervision session. When used, the supervisee should be encouraged to explore what they believe should have happened and apply learning from prior sessions. At subsequent meetings the incident is further explored to reflect upon new learning applied and whether what was hoped for was actually achieved. 


\section{(1e) Relationship}

It is important for supervisor and supervisee to be open to questions and feedback, which requires skill on behalf of the supervisor because they are senior in the hierarchical arrangement. The supervisee giving feedback to the supervisor about their facilitation style is also of value. For example, what they said or did that was most or least helpful? The supervisee should be the one to:

- Set most of the agenda.

- Talk about what they want.

- Have no record made of personal disclosures.

- Be given protected space, i.e., private with no interruptions.

- Talk about difficulties and vulnerable feelings without being judged It is important to note that there are differences between non-directive and directive approaches (see Table 2) (NES, 2019c)

Table 2: Differences between facilitating and mentoring (NES, 2019c)

\begin{tabular}{|l|l|}
\hline Non-Directive (facilitating) & Directive (mentoring) \\
\hline Active \& constructive listening & Advising \\
\hline Reflecting back \& clarifying & Giving feedback \\
\hline Summarising & Instructing \\
\hline Asking questions \& exploring & Suggesting \\
\hline Affirming & Sharing ideas \\
\hline Empathising & \\
\hline
\end{tabular}

\section{(2) Maintaining FOCUS}

\section{(2a) Issues}

There may be barriers towards implementation of a new clinical supervision system (NES, 2019). For example, some midwives may feel ambivalent towards the new model or be resistant to it. Objections may include time restrictions, staffing, or implementing a poorly facilitated and unstructured supervision model.

\section{(2b) Objectives}

To assist the supervisee to narrow focus and enable depth of exploration, the following questions may be useful: 
- What would you like (supervisee) to focus on in this session?

- I heard (reflect back)...Which of these do you think would be most helpful to focus upon?

It is important to outline and confirm the objectives of the session before proceeding.

\section{(2c) Presentation}

There are a variety of tools that the supervisor can use to aid analysis of the chosen clinical scenario. For example, The Ladder of Inference is an effective tool to aid understanding of why people instigate conflict with each other and fail to resolve the situation (Argyris 1970) (see Table 3).

Table 3: The ladder of inference (adapted from Argyris \& Schön, 1974)

\begin{tabular}{|c|c|c|c|}
\hline Actions & $\begin{array}{l}\text { You colleague says to you: } \\
\text { "You managed that situation } \\
\text { just the way I expected a } \\
\text { midwife in this unit would!" }\end{array}$ & Actions & $\begin{array}{l}\text { When your colleague suggests } \\
\text { that you work with her on a } \\
\text { project, you engage because } \\
\text { you think she values your } \\
\text { standard of work. }\end{array}$ \\
\hline Beliefs & $\begin{array}{l}\text { You believe that your new } \\
\text { colleague has insulted you by } \\
\text { stating that the midwives in } \\
\text { this unit are incompetent. }\end{array}$ & Beliefs & $\begin{array}{l}\text { You interpret that your new } \\
\text { colleague has complemented } \\
\text { both yourself and your peers } \\
\text { through stating: } \\
\text { "You managed that situation } \\
\text { just the way I expected a } \\
\text { midwife in this unit would!" }\end{array}$ \\
\hline Conclusions & $\begin{array}{l}\text { You conclude that the level of } \\
\text { your work is not up to scratch, } \\
\text { and that perhaps the unit is } \\
\text { substandard. }\end{array}$ & Conclusions & $\begin{array}{l}\text { Your new colleague concluded } \\
\text { that the level of your work will } \\
\text { be similar to the high } \\
\text { standards of your colleagues. }\end{array}$ \\
\hline Assumptions & $\begin{array}{l}\text { You assume that your } \\
\text { colleague values her own skills } \\
\text { and training more highly than } \\
\text { yours. }\end{array}$ & Assumptions & $\begin{array}{l}\text { Your colleague assumes that } \\
\text { you are good at your job } \\
\text { because she has been } \\
\text { impressed by the high quality } \\
\text { skills of your colleagues. }\end{array}$ \\
\hline Meanings & $\begin{array}{l}\text { When your new colleague } \\
\text { suggests that you work with } \\
\text { her on a project, you make an } \\
\text { excuse not to engage because } \\
\text { you think she is just being } \\
\text { polite. }\end{array}$ & Meanings & $\begin{array}{l}\text { Your colleague asked you to } \\
\text { work with her on the project } \\
\text { because she meant it when } \\
\text { she said: } \\
\text { "You managed that situation } \\
\text { just the way I expected a } \\
\text { midwife in this unit would!" }\end{array}$ \\
\hline
\end{tabular}

When a conflict scenario is raised, the supervisor guides the midwife to work down The Ladder of Inference to explore each stage of 'what' they were thinking and 'why' in the given situation. Together they then progress back up the ladder as they 
develop a new sense of reasoning. For example, consider a time you found yourself confused about why another person interpreted something you said in a way you never intended, or a time when you found yourself annoyed by another person's comments or behaviour and concluded that they do not like you. As illustrated in Table 3, The Ladder of Inference is a way of describing how the supervisee can move from a comment to conclusion through progressing a sequence of mental steps. It is important to avoid climbing The Ladder of Inference in a direction that leads to detrimental conclusions, and simply accept that drawing inferences from what others say or do is based upon past experience. Also, the possibility should be considered that assumptions made by the supervisee may actually be correct.

\section{(2d) Priorities}

It is important for the midwife (supervisee) to prepare for each supervision session, with ground work promoting more efficient use of time and facilitation of a more considered reflection. Preparation may include:

- Thinking about an event to bring to the session.

- Reviewing achievements since last session.

- Considering learning from prior sessions and how they have influenced practice.

- Writing a reflective account.

\section{(3) The importance of SPACE}

Time, privacy and a suitable environment are key components of creating space to support effective supervision (NES, 2019).

\section{(3a) Collaboration}

A collaborative and trusting relationship is necessary for supervision to be effective and successful. The new Scottish Clinical Supervision Model (NES, 2019) emphasises 3 elements that are designed to build resilience: (1) Respond, (2) Reflect, and (3) Restore. The goal is to build resilience through exploring Reflections upon a clinical event and how the midwife (supervisee) Responded and why and during process attempt to Restore emotions to a comfortable position. Post Responding and during the process of Reflecting, the Restore component involves the supervisor placing emphasis upon processing emotions and building the 
supervisee's resilience to cope in similar future events. The Restore approach is designed to help clinicians become more effective in the workplace. In turn, this expectantly will reduce sick time and improve relationships with colleagues (Wallbank \& Woods, 2012). In the role of facilitator, the supervisor does not make the choices. Instead, their role is to create opportunity for the midwife to select options and appropriate responses.

(3b) Investigation

The key rationale for reflecting upon practice is because experience alone does not lead to insightful learning (Loughran, 2002). The supervisee is not simply reflecting upon past actions and events, but also takes a conscious look at their emotions, experiences and responses in attempts to reach a higher level of understanding (Paterson \& Chapman, 2013). It is important to note that people repetitively engage in self-limiting behaviours due to preferred ways of thinking and responding (Turesky et al., 2011), with challenge to concepts and assumptions helpful towards breaking these cycles (Helsing et al., 2008). It has been shown that learning organizations which have invested in supervision processes that engage reflection on practice are more effective at inaugurating change (Aviolo et al., 2010). Reflection that is well conducted can shift anxiety into positive energy for action and address the gap between actual and desirable practice. From the many reflective models available to aid analysis of a scenario, two options are now presented:

\section{(1) Gibbs 1988}

Gibbs reflection cycle (1998) provides a circuit of steps that can be used to guide critical discussion of a clinical event (see Figure 2): 


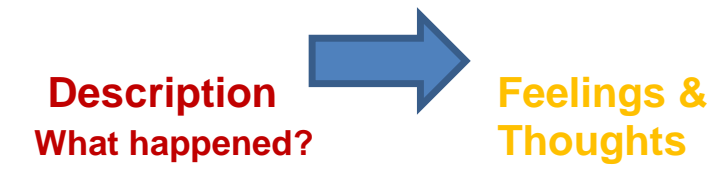

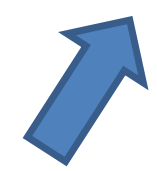

Action plan

If occurred again;

What would you do?

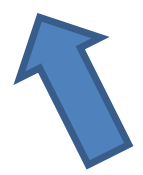

Conclusion

What else could be done?

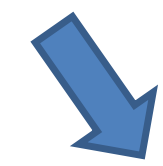

Evaluation

Good/Bad

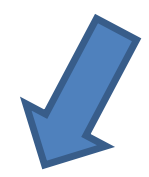

Analysis

What sense can

be made?

Figure 2: Cycle of steps used in Gibbs (1988) reflective model

(Adapted from Gibb's, 1988)

(2) Kolb's Model (1984)

Kolb's Model (1984) consists of the four elements outlined in Figure 3, with this cyclic model commencing at any one point.

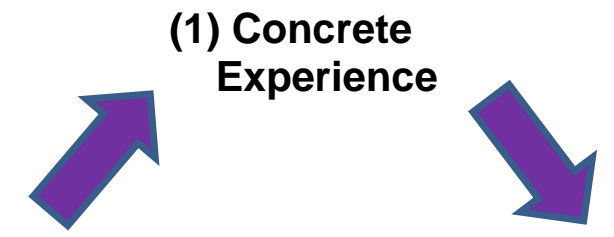

(4) Active

Experimentation

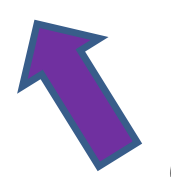

(3) Abstract

Conceptualisation
(2) Reflective

Observation

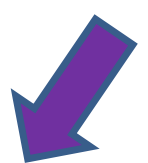

\section{n}

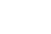

Figure 3: Kolb's model of reflection (Adapted from Kolb, 1984) 
(3c) Challenge

During critical analysis, it is important to facilitate the midwife explore issues from several perspectives before action planning. Useful questions begin with 'what', 'how' or 'when'. For example (Kolb, 1984):

- How were you feelings....?

- How do you think the woman was feeling....?

- What makes you think that.....?

- When did you first notice that your emotions had changed?

- What was going through your mind at the time?

- What was your intention when you did that.....?

- How much do you understand their behaviour.....?

- Describe.....or tell me about.....?

(3d) Containment

The supervisor has responsibility for organising a safe space in which supervision can take place with minimal interruption (NES, 2019). In this space, the supervisor must be totally present and remind self in advance of key points from prior discussions. The supervisor must maintain confidentiality, be reliable, adhere to agreed appointments, and be mindful of the pre-written contract. It is important that the supervisor identifies and acts appropriately regarding unsafe, unethical or illegal practice. Emotions expressed should be contained within this safe space.

(3e) Affirmation

It is important to provide affirmations (assertions, support, verification, confirmation, encouragement) (NES, 2019). Given this support, the midwife (supervisee) is more likely to reflect upon values and is less likely to experience distress and react defensively when confronted with information that contradicts or threatens their sense of self. Such affirmations help coping with threat or stress and as such act towards improving performance.

\section{(4) Building a BRIDGE}

At the end of the supervisor session, it is important for the midwife to leave with a clearly summarised picture of events (NES, 2019): 


\section{(4a) Consolidation}

To consolidate the supervision session, goal setting will facilitate the midwife (supervisee) to identify what changes in practice are best and what they might look like (NES, 2019). This involves them considering what they could be doing or how they may be feeling if they were to implement aspects surrounding the event differently.

(4b) Information giving

Having shared and researched information that relates to the incident explored, the following are addressed (NES, 2019):

(1) Applying research evidence to why a new approach works.

(2) Sharing clinical expertise, judgment, experience and identifying benefits of potential interventions.

(3) Considering women, partner and families preferences and values.

\section{(4c) Goal setting}

The bridge component of the supervision model is underpinned by motivation and jointly discussed goal-setting (NES, 2019). Goal-setting involves setting objectives designed to improve subsequent performance. These goals should be set with clarity, challenge, commitment, feedback, and be relevant to task complexity.

\section{(4d) Action planning}

An action plan requires to be written which outlines steps required to reach the goals outlined (NES, 2019). The action plan can be written as a sequence of steps taken to inaugurate change in practice. The supervisor and supervisee negotiate and agree the action plan outlined.

\section{(4e) Client's view}

The supervisor requires to place the supervisee at the centre of discussions and perceive them as an equal partner in planning, developing and monitoring of care they provide (NES, 2019). This involves placing the midwife at the centre of decisionmaking and seeing them as experts working alongside their supervisor to gain best outcome. Being compassionate and thinking about matters from the midwife's perspective is key during this process. 


\section{(5) The REVIEW}

Review and evaluation of prior actions can be achieved when the goals set are specific and measurable (NES, 2019). SMART is a useful acronym that could be used when writing objectives:

$$
\begin{aligned}
& S=\text { Specific } \\
& M=\text { Measureable } \\
& A=\text { Achievable } \\
& R=\text { Relevant } \\
& T=\text { Time-bound }
\end{aligned}
$$

Goals written should have a distinct purpose and be written in a way that directs full completion of the task in hand (SAMHSA, 2019).

\section{(5a) Feedback}

The review offers opportunity to explore with the supervisee if objectives from prior supervision sessions are still relevant and if there is need or desire to continue with discussions surrounding chosen topics (NES, 2019).

\section{(5b) Grounding}

Processes can be challenging, simply because it requires the midwife (supervisee) to share thoughts that may render them vulnerable. To gain the best from clinical supervision, it is key for the midwife to trust their supervisor. In response, the supervisor must treat any declarations with respect and confidentiality. Issues should only be shared post recorded agreement in relation to what will be disclosed and to whom (NES, 2019).

\section{(5c) Evaluation}

Some form of standardised evaluation of the supervision process requires to be developed to measure benefits at both an individual and organisational level. Evaluations can be conducted verbally and through use of a structured survey (NES, 2019).

\section{(5d) $\underline{\text { Assessment }}$}

It is important to assess the supervisee's views of the supervision process (NES, 2019). That is, what has gone well and what has not, in relation to any decided actions taken post supervision. An assessment could involve the midwife writing a 
structured reflection on practice essay, using a reflective model such as Gibbs (1988) or Kolb's (1984). Post completion, this essay may be placed in the midwife's personal portfolio and used as part of revalidation for the NMC.

\section{$\underline{\text { Summary }}$}

The aforementioned steps in the supervision process are cyclic, with supervision commencing at any point in the cycle. A summary and round-up of the cyclical nature of the Scottish Clinical Supervision Model can be viewed in Figure 4 (NES, 2019d).

\section{This cyclical model provides a useful framework to formulate your approach and practice}

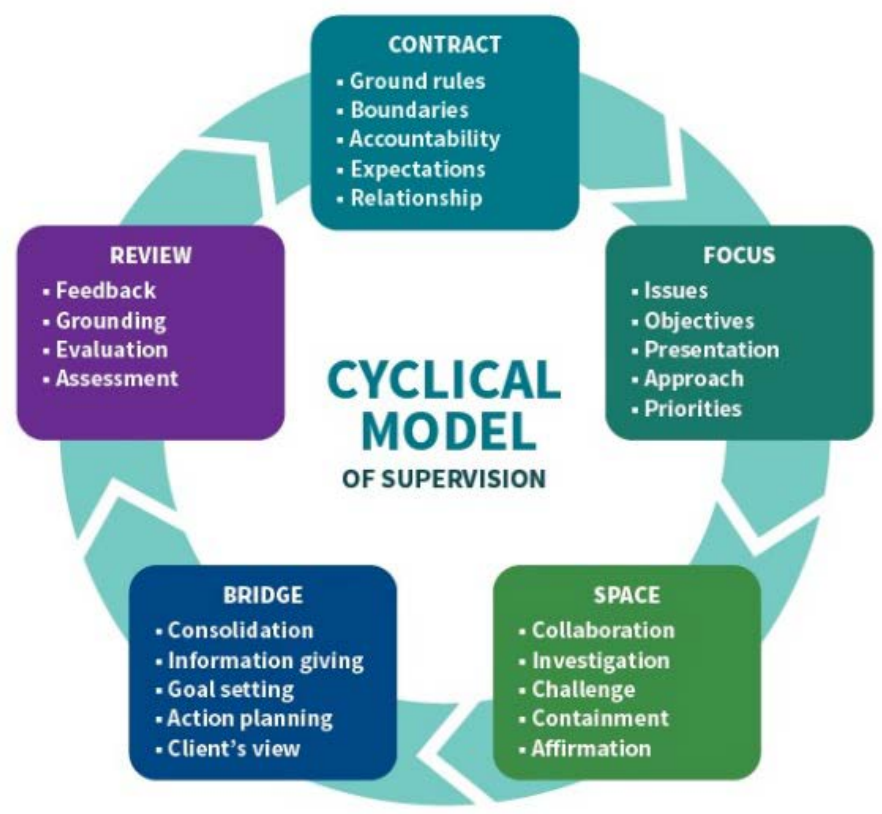

Figure 4: The cyclical model of supervision (NES, 2019d).

A summary of processes involved in the Scottish Clinical Supervision Model have been captured in a set of laminated cards that can be carried in the pocket of the supervisor (see Figure 5) (NES, 2019e). 


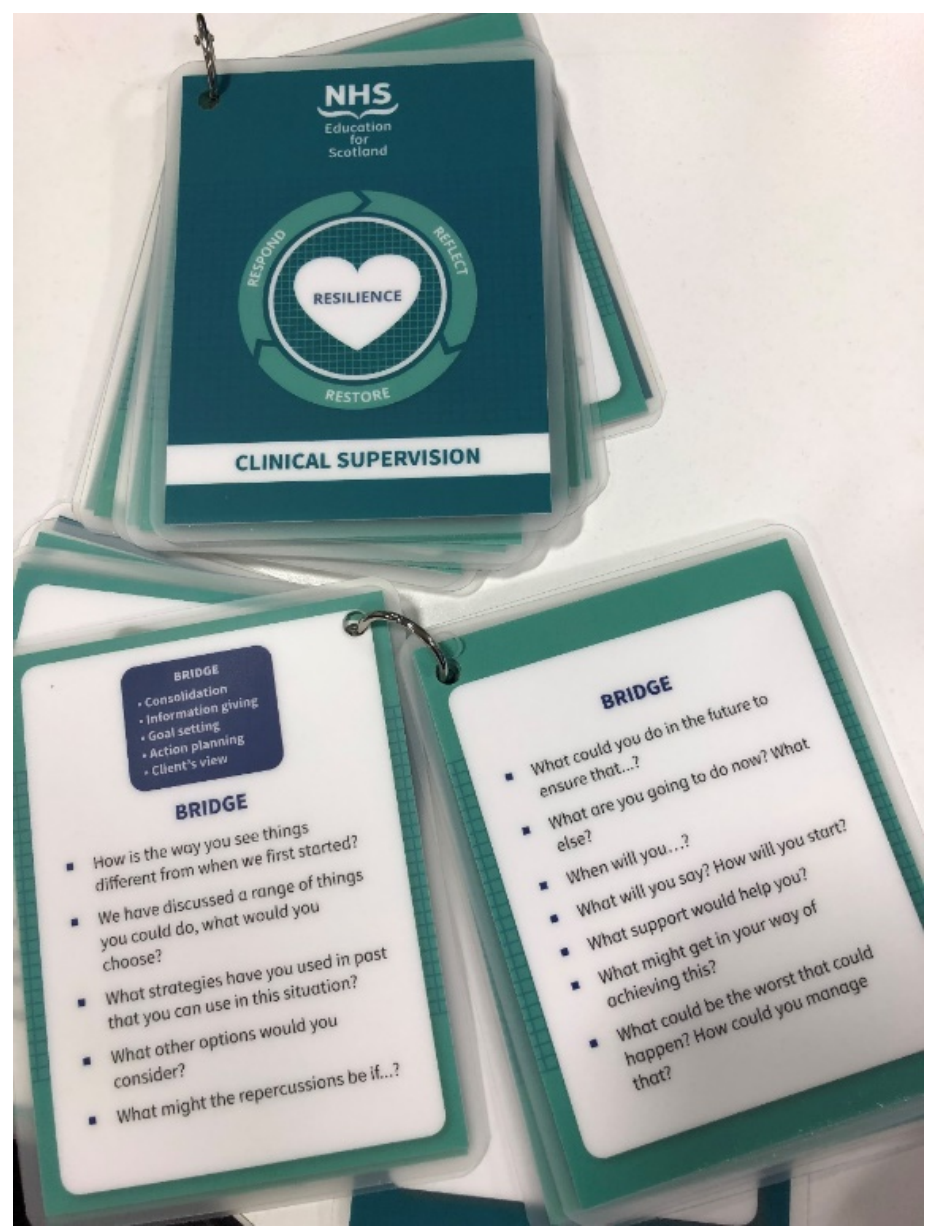

Figure 5: Pocket sized laminated cards that outline the Scottish Clinical Supervision Model (NES, 2019e)

\section{Conclusion}

The Scottish Government (SG) and NHS Education for Scotland (NES) has worked with the NHS Health Boards to develop a new employer-led Scottish Clinical Supervision Model. This paper outlines sequential steps involved in this new supervision process. When used, this refreshed approach to midwifery supervision seeks to develop midwives' resilience and cultivate their practice, with the ultimate aim of improving services and providing safer outcomes for women, infants and families through reflection on practice. This new model takes a person-centred approach, which includes coaching methods that teach midwives to respond, reflect, and restore self. Education that supports the new Scottish Clinical Supervision Model is free to access at: https://www.nes.scot.nhs.uk/education-and-training/by-themeinitiative/maternity-care/about-us/clinical-supervision.aspx 


\section{References}

Argyris C (1970) Intervention theory and method: a behavioral science view. Mass, AddisonWesley, Reading (UK).

Argyris, C, Schön DA (1974) Theory in Practice: Increasing Professional Effectiveness. Jossey-Bass, San Francisco.

Avolio BJ, Avey JB, Quisenberry D (2010) Estimating return on leadership development investment. The Leadership Quarterly 21(4): 633-644.

Beaumont E, Hollins Martin CJ (2016) Heightening levels of compassion towards self and others through use of compassionate mind training. British Journal of Midwifery 24(11): 3-12.

Bishop V, Sweeney (2006) In Bishop V ed (2007) Clinical Supervision in Practice 2nd Ed. Palgrave-Macmillan, Basingstoke (UK).

Care Quality Commission (2013) Supporting information and guidance: supporting effective clinical supervision. Care Quality Commission, London.

Cassedy P (2010) First steps in clinical supervision: guide for healthcare professionals. Open University Press, Maidenhead.

Gibbs G (1988) Learning by doing: a guide to teaching and learning methods. Further Education Unit, London.

Hawkins P, Shohet R (2012) Supervision in the helping professions 4th ed. Open University Press, Maidenhead.

Health and Care Professions Council (2017) Renewing your registration. Available at: www.walsallsocialcareworkforce.co.uk/test/303

Helsing D, Howell A, Kegan R, Lahey LL (2008) Putting the development in professional developing understanding and overturning of educational leaders immunities to change. Harvard Educational Review 78(3): 437-465.

Klimecki O, Singer T (2012) Empathic distress fatigue rather than compassion fatigue? Integrating findings from empathy research in psychology and social neuroscience. In Oakley B, Knafo A, Madhaven G, Wilson DS eds (2011) Pathological Altruism. Oxford University Press, New York 368-83.

Kolb DA (1984) Experiential learning. Prentice Hall, Englewood Cliffs, New Jersey (USA).

Loughran J (2002) Effective reflective practice: in search of meaning in learning about teaching. Journal of Teacher Education 53(1): 33-43.

NHS Education for Scotland (NES) (2019) Clinical Supervision Site. Available at: https://www.nes.scot.nhs.uk/education-and-training/by-theme-initiative/maternity-care/aboutus/clinical-supervision.aspx

NHS Education for Scotland (NES) (2019a) Goals for building resilience. Slide used by teaching team at workshops to support the clinical supervision digital resource: Clinical Supervision. Available at: https://www.nes.scot.nhs.uk/education-and-training/by-themeinitiative/maternity-care/about-us/clinical-supervision.aspx 
NHS Education for Scotland (NES) (2019b) Summary of steps involved in the Scottish Clinical Supervision Model: NES supervision laminated cards (Figure 5). NES Clinical Supervision Resources. https://www.nes.scot.nhs.uk/education-and-training/by-themeinitiative/maternity-care/about-us/clinical-supervision.aspx

NHS Education for Scotland (NES) (2019c) Differences between facilitating and mentoring: NES Clinical Supervision Resources. https://www.nes.scot.nhs.uk/education-and-training/bytheme-initiative/maternity-care/about-us/clinical-supervision.aspx

NHS Education for Scotland (NES) (2019d) (2019) The cyclical model of supervision. Clinical supervision for midwives (Unit 2): fundamentals of supervising others-digital resources (Slide 6). Available at: https://www.nes.scot.nhs.uk/media/3963020/CSM\%20Unit\%202.pdf

NHS Education for Scotland (NES) (2019e) NES supervision laminated cards of summary of steps. Photograph taken by the NES clinical supervision teaching team (authors). NES Clinical Supervision Resources. https://www.nes.scot.nhs.uk/education-and-training/bytheme-initiative/maternity-care/about-us/clinical-supervision.aspx

Nursing and Midwifery Council (2017a) Proposed changes to midwifery supervision. Available at: https://www.nmc.org.uk/standards/midwifery/changes-to-midwifery-supervision/ Nursing and Midwifery Council (2017b) Revalidation. Available at: revalidation.nmc.org.uk/ Page S, Wosket V (2001) Supervising the counsellor 2nd ed. Brunner-Roultedge, Hove (UK).

Paterson C, Chapman J (2013) Enhancing skills of critical reflection to evidence learning in professional practice. Physical Therapy in Sport 14(3): 133-138.

Proctor B (1988) Supervision: a cooperative exercise in accountability. In Marken M, Payne M, eds (1997) Enabling and ensuring. National Youth Bureau and Council for Education and Training in Youth and Community Work: Leister (UK).

Proctor B (2011) Group Supervision a Guide to Creative Practice 2nd ed. Sage: London (UK).

Raab K (2014) Mindfulness, self-compassion, and empathy among health care professionals: a review of the literature. Journal of Health Care Chaplaincy 20(3), 95-108.

SAMHSA Native Connections (2019). Setting goals and developing Specific, Measurable, Achievable, Relevant, and Time-bound objectives. Available at:

https://www.samhsa.gov/sites/default/files/nc-smart-goals-fact-sheet.pdf

Scottish Government (SG) (2010) Relationships, rights and recovery: refreshed: the report of the national review of mental health nursing in Scotland. Available at:

library.nhsggc.org.uk/mediaAssets/Mental\%20Health\%20Partnership/Rights\%20Relationshi ps\%20\&\%20Recovery-ScotGov2010.pdf

Scottish Government (2013) Everyone matters: 2020 workforce vision. Available at: https://www.gov.scot/publications/everyone-matters-2020-workforce-vision/pages/0/

Scottish Government (SG) (2017) Transitioning supervision of midwives taskforce. Scottish Government 
Scottish Government (2017). Nursing 2030 vision; promoting confident, competent and collaborative nursing for Scotland's future. Scottish Government 2017.

Sheen K, Slade P, Spiby H (2014) An integrative review of the impact of indirect trauma exposure in health professionals and potential issues of salience for midwives. Journal of Advanced Nursing 70: 729-743.

Turesky EF, Gallagher D (2011). Know thyself: coaching for leadership using Kolb's experiential learning theory. The Coaching Psychologist 7(1): 5-14.

Wallbank S (2010) Effectiveness of individual clinical supervision for midwives and doctors in stress reduction: findings from a pilot study. Evidence Based Midwifery 8: 65-70

Wallbank S, Woods G (2012) A healthier health visiting workforce: findings from the Restorative Supervision Programme. Community Practitioner 85(11): 20-23. 